\title{
Computational fluid dynamics analysis of flow through immobilized catalyzed packed bed reactor for removal of 4-chlorophenol from wastewater
}

\author{
Sudhansu Sandhibigraha ${ }^{1}$, Soumya Sasmal ${ }^{2}$, Tarun Kanti Bandyopadhyay ${ }^{1}$, Biswanath Bhunia ${ }^{3^{\dagger}}$ \\ ${ }^{1}$ Department of Chemical Engineering, National Institute of Technology, Agartala, Agartala-799046, India \\ ${ }^{2}$ Department of Biological Sciences and Engineering, Netaji Subhas University of Technology, New Delhi-110078, India \\ ${ }^{3}$ Department of Bio Engineering, National Institute of Technology, Agartala, Agartala-799046, India
}

\begin{abstract}
The computational fluid dynamics (CFD) simulation of the packed bed reactor (PBR) was carried out using ANSYS Fluent software. The various process parameters, such as inlet concentration of 4-chlorophenol (4-CP), flow rate, bed height, and porosity, were optimized to predict maximum biodegradation of 4-CP in immobilized catalyzed PBR. The geometrical mesh of the PBR was constructed using Gambit software, and a mesh size of 236995 was selected from the grid-independent study. A laminar flow model was used to understand the hydrodynamics as well as concentration profile of 4-CP inside the PBR using Fluent software. Through CFD, the effect of the flow rate, inlet concentration, and the bed height and porosity of the immobilized catalyst bed on the static pressure, mass imbalance, velocity, and stress-strain field inside the PBR was visualized. CFD simulation study predicted that maximum biodegradation of 4-CP was found in the presence of $500 \mathrm{mg} / \mathrm{L}$ of inlet concentration of $4-\mathrm{CP}, 4 \mathrm{~mL} / \mathrm{min}$ of flow rate, $18 \mathrm{~cm}$ of bed height and 0.375 of porosity. An experimental study was conducted for wastewater flow through the B. subtilis MF447840.1 immobilized catalyzed PBR to remove the 4-CP in the laminar flow region. It was evident that CFD simulated results agreed well with experimental values.
\end{abstract}

Keywords: Bacillus subtilis, Computational fluid dynamics, Degradation, Packed bed reactor, 4-chlorophenol

\section{Introduction}

US Environmental Protection Agency has enlisted 4-chlorophenol (4-CP) as a pollutant since it shows carcinogenic and recalcitrant properties [1]. The various industries have used 4-CP as raw material, and therefore, it has been found as a contaminant in effluents of pulp and paper, herbicide industries, biocide, leather tanning and dye [2]. Although4-CP concentration in effluent changes within 100 to $1,000 \mathrm{mg} / \mathrm{L}$ in various industries [3]. Therefore, 4-CP causes several problems in the aquatic environment and effects various diseases such as amebiasis, diarrhea, respiratory problems, dermal damage, and cancers [4]. Therefore, 4-CP in the effluent must be degraded by chemical industries before discharging to comply with environmental laws $[5,6]$. The chemical manufacturing is significantly imperative to financial prudence round the globe, playing a key role in progressions extending from the making of purified

This is an Open Access article distributed under the terms of the Creative Commons Attribution Non-Commercial License (http://creativecommons.org/licenses/by-nc/3.0/) which permits unrestricted non-commercial use, distribution, and reproduction in any medium, provided the original work is properly cited.

Copyright (C) 2020 Korean Society of Environmental Engineers drinking water to the production of various pharmaceutical bio-products. Therefore, it is an urge for biochemical engineers to ensure profitability within a fast growing and evolving marketplace alongside confirming content of pollutant within a certain limit.

There are several techniques, such as chemical oxidation, adsorption, extraction of solvent, photo mediated degradation, and advanced oxidation reported for the management of 4-CP containing wastewater [7, 8]. However, biological methods are advantageous and effective for 4-CP removal as the process is cost-effectivenessand does not produce toxic intermediates [9]. It is obvious that the types of bioreactor play a crucial role in wastewaters treatment process [10]. Packed bed reactors (PBRs) are the most commonly used reactors for biochemical manufacturing gas higher conversion per weight of catalyst was found compared to other catalytic reactors used in biochemical industry. However, the design of PBRs containing immobilized cells is major challenges for chemical engineers

Received April 30, 2019 Accepted November 25, 2019

${ }^{\dagger}$ Corresponding author

Email: bbhunia@gmail.com

Tel: 0381-2346-360 Fax: 0381-2346-360

ORCID: 0000-0003-1330-1606 
as proper immobilization techniques and design decides overall efficiency of bioremediation process [11]. PBRs are also used for several application linked with chemical processes, which include distillation, absorption, separation of chemical products, stripping, and various catalytic reactions. Owing to its versatile applications in various processes, the dimensions of the packed beds were differ impressively. PBR is consisted of a compartment, which is called channel or a tube where catalyst pellets or particles were kept. The fluid was flowed through the compartment and interaction between fluid and the catalyst leads to change the composition of substrate present in fluid [11].

The porous media model can be used for a variety of single-phase and multiphase flow problems, including flow through packed beds, filter paper, membranes, perforated plates, and flow distributors. The most common used reactors for chemical or biochemical processing applications are PBRs which are usually filled with solid catalyst particles. The degradation of effluents present in wastewater (4-chlorophenol + water) by this technique is widely implemented to treat various industrial effluents as well as improve the quality of industrial effluents [9, 12]. Since fluid behaviour plays a crucial role in overall efficiency in PBR, therefore, computational fluid dynamics (CFD) technique is utmost important to comprehend the fluid flow and mass transport locally through packed-beds. As fluid flow inside PBR is a complex phenomenon; therefore, prediction of hydrodynamics properties inside PBR is an expensive experimental method. To study reactor scale-up and understand the consequence of several factors on the performance of bioreactor, CFD analysis is highly necessary; however, it should be validated before applied realistically [13]. Amani \& Jalilnejad [2] developed a CFD model for simulating the dynamic performance of formaldehyde (FA) biodegradation, where biochemical reactions and fluid dynamics were studied. The study was carried out in batch-recycling as well as the continuous mode in PBR where disk-shaped Kissiris pieces were used for immobilization of Ralstonia eutropha. The validation of simulated CFD model was carried with the help of experimental data available in the literature for biodegradation [14]. Habibi et al. [15] experimented in plug flow PBR under semi pilot-scale to evaluate FA degradation process in continuous mode of operation. In this study, Ralstonia eutropha was immobilized on polyurethane foam, and the inlet concentration of FA was increased stepwise. The experimental data was successfully simulated with a CFD model where a biochemical reaction was combined with fluid dynamics [15]. In our previous manuscript [16], biodegradation of 4-CP was studied in a batch process using Bacillus subtilis MF447840.1, which can able to degrade 4-CP with the concentration of $1 \mathrm{~g} / \mathrm{L}$ within $40 \mathrm{~h}$. As per our knowledge concern, there are few studies reported on the prediction of hydrodynamics properties for biodegradation of 4-CP using CFD analysis, therefore, the prospective importance of these properties on 4-CP biodegradation in PBR has been emphasized by experiments with B. subtilis MF447840.1.

Herein this study, the CFD approach was employed to analyze the performance of packed bed bioreactor in three-dimensional manner with $B$. subtilis MF447840.1 immobilized bead for biodegradation of $4-\mathrm{CP}$ in the synthetic wastewater. The optimum process parameters so obtained from CFD simulation was employed for validation.

\section{Material and Methods}

\subsection{Chemicals}

4-CP was procured from Sigma, U.S.A. The magnesium sulfate, calcium chloride, nutrient broth, and agar powder were purchased from Hi-media, India. Other reagents used for this investigation, were molecular grade which were available commercially in India.

\subsection{Microorganism and Seed Culture}

B. subtilis MF447840.1 employed in the present investigation was purified from the water collected from drain of service center for Hyundai car, Agartala, India,and characterized [16]. The pure culture was inoculated in fifty milliliter media by the help of platinium loop and kept at $37^{\circ} \mathrm{C}$ in a shaker at $150 \mathrm{rpm}$. The media was composed of ammonium nitrate, $0.5 \mathrm{~g} / \mathrm{L}$; magnesium sulfate, $0.2 \mathrm{~g} / \mathrm{L}$; dipotassium phosphate, $0.5 \mathrm{~g} / \mathrm{L}$; monopotassium phosphate, $0.5 \mathrm{~g} / \mathrm{L}$ and calcium chloride, $0.02 \mathrm{~g} / \mathrm{L} .10 \mathrm{~mL}$ of trace element solution was added to one litter of inorganic medium. The composition of trace element solution $(\mathrm{g} / \mathrm{L})$ was ferrous sulfate, $0.3 \mathrm{~g} / \mathrm{L}$; manganese sulfate, 0.05 g/L; cobalt chloride, $0.1 \mathrm{~g} / \mathrm{L}$; sodium molybdate, $0.034 \mathrm{~g} / \mathrm{L}$; zinc sulfate, $0.04 \mathrm{~g} / \mathrm{Land}$ copper sulfate, $0.05 \mathrm{~g} / \mathrm{L}$ [16]. 4-CP with the concentration of $500 \mathrm{mg} / \mathrm{L}$ was initially added to the mediafor carbon source, and the $\mathrm{pH}$ of the media was maintained to 7.4. The subculturing of bacterium was carried out after $1 \mathrm{~d}$ of interval to the similar medium, which was supplemented with $1 \mathrm{~g} / \mathrm{L}$ of 4 -CP. The bacterial cells $\left(\mathrm{OD}_{600}\right.$ $\mathrm{nm} \approx 0.1$ ) were centrifuged after the overnight growth and repeatedly washed with phosphate buffer saline solution ( $\mathrm{pH}$ 7.4). The centrifugation was performed for precipitation of bacteria, which were used for alginate bead preparation.

\subsection{Preparation of Ca-alginate Beads Immobilized with Bacterial Cell}

The bacterial cells, as precipitated above, were re-suspended in a solution containing $4 \%$ sodium alginate and bacterial cell density was maintained to $4.2 \mathrm{~g} / \mathrm{L}$. The various needles were used in different batch experiments to discharge the alginate-bacterial cell suspensions into a sterilized $\mathrm{CaCl}_{2}$ solution (5\%) with continuous stirring. Subsequently, bead with different spherical size and shape were formed upon contact between sodium alginate drops and calcium chloride solution. The calcium alginate beads immobilzed with B. subtilisMF447840.1 were kept in $\mathrm{CaCl}_{2}$ solution and washed with distilled water. The beads were keptat $4^{\circ} \mathrm{C}$ for $12 \mathrm{~h}$.

\subsection{Analytical Procedures}

UV-visible spectrophotometer was used for measurement of cell concentration, which was carried out at $600 \mathrm{~nm}$ of wavelength. A calibration curve was drawn between the dry cell weights versus optical density $\left(\mathrm{OD}_{600}\right)$ to compute the biomass weight from optical densities $\left(\mathrm{OD}_{600}\right)$ of the broth culture [16]. The residual 4-CP was measured by taking the absorbance of filtrate at $298 \mathrm{~nm}$ achieved after centrifugation of broth for $10 \mathrm{~min}$ at $10,000 \mathrm{~g}$, and followed by filtration through $0.22-\mu \mathrm{m}$ filter [9, 16, 17].

\subsection{Experiment}

The immobilized catalyst packed bed is prepared by filling different-sized 

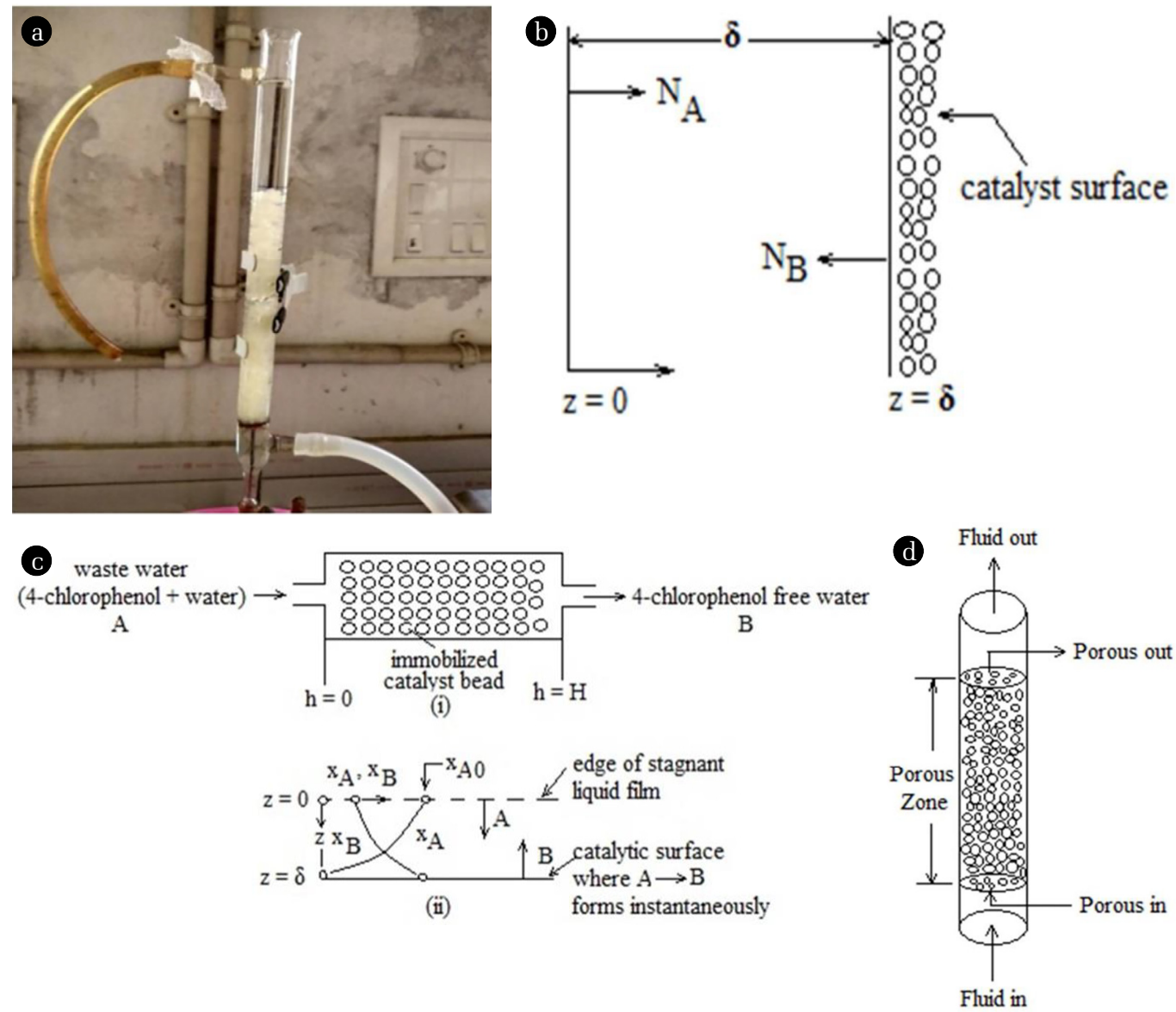

Fig. 1. (a) Packed bed reactor column, (b) Diffusion of A and heterogeneous reaction on immobilized catalyst surface (c): (i) Schematic diagram of catalytic packed bed reactor, (ii) idealized model diagram of the diffusion problem near the immobilized catalyst surface, (d) Porous zone model of packed bed reactor.

catalyst particles in a vertical tube (Fig. 1(a)) for various batch experiments. Inner diameter and height of PBR are 2 and $25 \mathrm{~cm}$, respectively. The thickness of the tube wall is $3 \mathrm{~mm}$. The diameter of the catalyst particles used for this study was 2, 4, and $6 \mathrm{~mm}$. The top portion of tube is open, and porous plate is kept at the bottom of tube to support the bed of catalyst. The porous plate helps to distribute the uniform flow of fluid over the cross-section available in PBR. The porosity inside the PBR for catalyst particles having a diameter of 2,4 , and $6 \mathrm{~mm}$ are $0.24,0.375$ and 0.49 , respectively. The wastewater (water +4 -chlorophenol) up-flows through the immobilized packed catalyst through the use of a peristaltic pump for $105 \mathrm{~min}$, and after the mass transfer through the reaction, it leaves the bed, yielding treated 4-chlorophenol and free water [18]. The effect of various flow rates (1.3, 2 and $4 \mathrm{~mL} / \mathrm{min})$, bed heights $(14,16$ and $18 \mathrm{~cm})$, inlet concentration of 4-CP $(500$, 750 and $1000 \mathrm{mg} / \mathrm{L}$ ) and porosity (0.49, 0.375 and 0.24 ) of bed were used to evaluate the percentage of 4-CP degradation in catalyst immobilized PBR.

The removal of 4-chlorophenol from the wastewater follows the following steps:

The transfer of 4-chlorophenol from the bulk liquid phase (wastewater) to the surface of the immobilized catalyzed bed accord- ing to flux equation [19] (Eq. (1)):

$$
N_{A}=k\left(C_{A b}-C_{A s}\right)
$$

Where $\mathrm{C}_{\mathrm{Ab}}\left(\mathrm{kg} \mathrm{mol} / \mathrm{m}^{3}\right)=$ concentration of 4-chlorophenol in the bulk liquid phase, $\mathrm{C}_{\mathrm{As}}\left(\mathrm{kg} \mathrm{mol} / \mathrm{m}^{3}\right)=$ concentration of 4-chlorophenol on the immobilized catalyzed surface, $\mathrm{k}(\mathrm{m} / \mathrm{s})=$ mass transfer coefficient and $\mathrm{N}_{\mathrm{A}}\left(\mathrm{kg} \mathrm{mol} / \mathrm{m}^{2} \cdot \mathrm{s}\right)=$ flux rate of 4-chlorophenol.

Transfer of 4-chlorophenol inside the catalyzed pore. This is followed by an instantaneous first-order chemical reaction. Here, 4-chlorophenol (A) diffuses to the surface of catalyst from the bulk liquid phase.The heterogeneous reaction is considered as spontaneous and irreversible: 4-chlorophenol (A) $\rightarrow$ 4-chlorophenol free water (2B). Because the mass transfer resistance is greater and chemical reaction is fast, the rate is controlled by the mass transfer, flux equation [19] (Eq. (2)):

$$
N_{A}=\left(c D_{A B} / \delta\right) \ln 1+x_{A 1} /\left(1+x_{A 2}\right)
$$

Here, c is total concentration $\left(\mathrm{kg} \mathrm{mol} / \mathrm{m}^{3}\right)$, and $\mathrm{D}_{\mathrm{AB}}$ is diffusivity 
of $4-\mathrm{CP}\left(\mathrm{m}^{2} / \mathrm{s}\right) . \mathrm{X}_{\mathrm{A} 1}$ and $\mathrm{X}_{\mathrm{A} 2}$ are mole fraction of 4 -CP in bulk and immobilized catalyzed surface, respectively. The reaction is considered as an instantaneous; therefore, $\mathrm{x}_{\mathrm{A} 2}=0$, as no A can exist next to the surface of catalyst.

After the degradation of 4-chlorophenol in the immobilized catalyzed return to the bulk of the liquid, the final result in 4-chlorophenol-free improved quality wastewater (Fig. 1(b) and (c)).

Efficiency and mass transfer controlling rate depends on the Thiele modulus, which is expressed by Eq. (3) [20].

$$
\phi=\sqrt{ } k a / D_{A} R
$$

$\Phi$ is thiele modulus. $k$ and $a$ are reaction rate constant $\left(\mathrm{s}^{-1}\right)$ and catalytic surface per unit volume, respectively $\left(\mathrm{m}^{2} / \mathrm{m}^{-3}\right) . D_{A}$ and Rare Diffusivity of $4-\mathrm{CP}\left(\mathrm{m}^{2} / \mathrm{s}\right)$ and radius of catalyst $(\mathrm{m})$.

Efficiency $\left(\eta_{A}\right)$ is expressed by Eq. (4) [20].

$$
\eta_{A}=3 / \phi^{2}[\phi \operatorname{coth} \phi-1]
$$

\subsubsection{General equation of packed bed}

\subsubsection{Laminar flow region}

For very low Reynolds numbers, the pressure drop [21] should vary with the first power of the velocity and inversely with the square of the channel size.The pressure drop for laminar flow in straight tubes was calculated using Haugen-Poiseuille equation and expressed by Eq. (5)

$$
\Delta P / L=32 \mu V_{a} / D^{2}
$$

Where $\Delta \mathrm{P}=$ pressure drop inside the straight pipe, $(\mathrm{kPa}) ; \mathrm{L}$ $=$ length of the pipe (m); $\mathrm{D}=$ diameter of the pipe (m); $\mu=$ viscosity of the fluid ( $\mathrm{kg} / \mathrm{m} \cdot \mathrm{s}$ ), and $\mathrm{V}_{\mathrm{a}}=$ average velocity of the fluid, $(\mathrm{m} / \mathrm{s})$.

The pressure drop inside the bed, can be calculated using Kozeny-Carman equation, which is appropriate for flow through beds at particle numbers up to approximately 1 and expressed by Eq. (6) [22].

$$
\Delta P / L=\left[150 \mu V_{0} / \Phi_{s}^{2} D_{p}^{2}\right]\left[(1-\varepsilon)^{2} / \varepsilon^{3}\right]
$$

Where $\Phi_{\mathrm{s}}=$ sphericity of the immobilized catalyst bed, $\mathrm{D}_{\mathrm{p}}=$ catalyst particle diameter(m); $\mathrm{V}_{0}=$ superficial or empty tower velocity $(\mathrm{m} / \mathrm{s})$ and $\varepsilon=$ void fraction of the bed. The Kozeny-Carman equation specifies that the flow of fluid is proportional to the pressure drop inside PBR and inversely related with the viscosity of fluid, which is equivalent to Ohm's law, i.e., $V_{c}=I R$. This statement is given by Darcy's law given by Eq. (7) [22].

$$
[\Delta P / L]=V_{0}[1 / \mu]
$$

Here, $\mathrm{I}=$ current, $\mathrm{V}_{0}=$ flow velocity, $\mathrm{V}_{\mathrm{c}}=$ voltage $=\Delta \mathrm{P}, \mathrm{R}$ $=$ resistance $=1 / \mu$.Burke-Plummer equation is an empirical correlation for the pressure drop in a packed bed at a high Reynolds number $\left(\operatorname{Re}_{\mathrm{p}}>1000\right)$ and given by Eq. (8) [22].

$$
\Delta P / L=\left[1.75 \rho V_{0}^{2} / \Phi_{s} D_{p}\right]\left[(1 ? \varepsilon) / \varepsilon^{3}\right]
$$

Ergun equation [22] (Eq. 9) can clarify the whole range of flow rates gained by assuming that the losses for viscous [23] and the kinetic energy are additive.

$$
\begin{aligned}
\Delta P / L= & {\left[150 \mu V_{0} / \Phi_{s}^{2} D_{p}{ }^{2}\right]\left[(1-\varepsilon)^{2} / \varepsilon^{3}\right]+} \\
& {\left[1.75 \rho V_{0}^{2} / \Phi_{s} D_{p}\right]\left[(1-\varepsilon) / \varepsilon^{3}\right] }
\end{aligned}
$$

\subsection{CFD Analysis}

\subsubsection{Model for the packed bed reactor}

A porous zone model is used for the packed bed analysis (Fig. 1(d)). The porous zone model follows the viscous laminar flow model at a small Reynolds number. Therefore, the model equation is stated by Eq. (6), considering the surface velocity, $V_{0}=V$.

To recover the case of simple homogeneous porous media, Eq. (10) was used.

$$
s_{i}=-\left[(\mu / \alpha)\left(v_{i}\right)+c_{2} 1 \frac{1}{2} \rho|v| v_{i}\right]
$$

where in momentum equation $\mathrm{S}_{\mathrm{i}}$ is called the source term. The magnitude of the velocity is expressed with $|\mathrm{v}|$. The permeability is expressed with $\alpha$, and the inertial resistance parameter is expressed with $\mathrm{C}_{2}$. It indicates simply specify D and C at diagonal matrices with $1 / \alpha$ and $\mathrm{C}_{2}$, respectively, on the diagonals (and zero for the other elements). Darcy's law can be expressed by Eq. (11) in porous media.

$$
\Delta P=[-\mu / \alpha]\left[V_{0}\right]=[-\mu / \alpha][V]
$$

Permeability can be expressed as

$$
\alpha=\left[D_{p}^{2} / 150\right]\left[\varepsilon^{3} /(1 ? \varepsilon)^{2}\right]
$$

The coefficient for viscous resistance is expressed as $1 / \alpha$. However, for multiphase flow, viscous resistance is expressed as reciprocal of effective permeability. Where $\mu$ and $D_{p}$ are viscosity and mean particle diameter, respectively. $L$ and $\varepsilon$ are abed length and void fraction, respectively.

\subsubsection{Inertial losses at porous media}

The constant $\mathrm{C}_{2}$ (in Eq. (10)) at higher velocities modifies for inertial losses inside the porous medium. This constant can be observed as a loss coefficient per unit length alongside the direction of flow. Therefore, the pressure drop is identified as a function of the dynamic head. If modelling of a perforated plate or tube is carried out, the elimination of permeability term can be done sometimes. In that case, the inertial loss term [24] will be used alone and a simplified equation for porous media will be developed (Eq. (13))

$$
\Delta P=-\sum_{j=1}^{\varepsilon} C_{2 i j} \frac{1}{2} \rho V_{j}[V]
$$

The pressure jump coefficient is expressed with $\mathrm{C}_{2} . V$ and $\rho$ are the velocity and density of the fluid. The magnitude of the velocity is expressed with $|\mathrm{v}| . \mathrm{C}_{2}$ is given by Eq. (14).

$$
c_{2}=\left[3.5 / D_{p}\right]\left[(1-\varepsilon) / \varepsilon^{3}\right]
$$

$\mathrm{C}_{2}$ is specified the coefficient for inertial resistance. 


\subsubsection{Boundary condition}

The velocity of 4-CP containing waste water through tubes was considered as the velocity of fluid in inlet boundary condition, while waste water coming from the outlet of PBR as a form of outlet pressure was defined as the boundary condition for outlet.The packed bed is considered as a porous zone. Porous zone of PBR was considered between inlet and outlet of fluid. Therefore, boundary condition was considered between porous in and porous out. As the no-slip condition is assumed in the reactor wall side, therefore, the velocity at the wall is assumed to be zero. Additionally, the radius of immobilized catalyst particle inside PBR is equal and denoted by R. Sphericity of all immobilized particles are equal $\left(\Phi_{\mathrm{s}}=1\right)$ [25] and equal void fraction of bed (porosity is the same for identical particle size). Since fluid velocity was very less; therefore, fluid behavior inside PBR is considered as the laminar and viscous laminar porous pressure-based model is used in this present study. Gambit software was used for designing of PBR having a radius of $0.0075 \mathrm{~m}$ and a height of $0.18 \mathrm{~m}$. The wastewater used in this study was considered as Newtonian incompressible isothermal fluid. The fluid is considered a single phase as solute 4-CP concentration is considered to be low, i.e., dilute concentration.

\subsubsection{Governing equation}

\subsubsection{Equation for continuity or mass balance}

The equation for continuity or mass balance under the steady-state of fluid flow through PBR is stated by Eq. (15).

$$
\nabla \cdot \mathbf{V}=\mathbf{0}
$$

Where, $=\mathrm{i}(\partial / \partial \mathrm{x})+\mathrm{j}(\partial / \partial \mathrm{y})+\mathrm{k}(\partial / \partial \mathrm{z})$

Here, i, j, k are unit vectors for $\mathrm{x}, \mathrm{y}, \mathrm{z}$ are coordinates, and nabla is represented by.

\subsubsection{Momentum balance equation}

The steady-state momentum equation for Newtonian fluid [26] through the packed bed reactor can be defined by Eq. (17).

$$
\rho \mathrm{V} \nabla \mathbf{V}=\mu\left(\nabla^{2}\right) \mathbf{V}-\nabla \mathrm{P}
$$

The equation is used when the convective term is combined with the concentration and reaction. Therefore, the unsteady-state mass transfer equation can be written by Eq. (18).

$$
\partial \mathrm{C}_{\mathrm{A}} / \partial \mathrm{t}+\left(\mathbf{u} \cdot \boldsymbol{\nabla} \mathrm{C}_{\mathrm{A}}\right)-\mathrm{D}_{\mathrm{A}} \nabla^{2} \mathrm{C}_{\mathrm{A}}=\mathrm{R}_{\mathrm{A}}
$$

For PBR, $\partial \mathrm{C}_{\mathrm{A}} / \partial \mathrm{t}=0$ as steady-state assumption. Bulk flow term is neglected $(\mathbf{u}=0)$ as dilute solutions were used in the present study. Therefore, the second part of Eq. (17) is zero. For the first-order reaction of $A$ where $A$ becomes exhausted, therefore, $R_{A}=-k_{A}$ $\mathrm{kg} \mathrm{mol} / \mathrm{s} \cdot \mathrm{m}^{3}$ and yields for steady-state are $\mathrm{D}_{\mathrm{A}} \partial^{2} \mathrm{C}_{\mathrm{A}} / \partial \mathrm{z}^{2}=\mathrm{kC}_{\mathrm{A}}$.

\section{Results and Discussion}

The performance evaluation of PBR was studied about 4-CP biodegradation. Packing materials used in PBR was alginate bead where bacteria were immobilized. The various process parameters such as flow rate, inlet concentration, bed height, and porosity of bead were optimized to achieve maximum biodegradation of 4-CP. Initially, experiments were performed to appraise the optimum level of all process parameters to achieve a higher amount of 4-CP degradation in PBR. After that, the CFD study was performed to comprehend the effect of various process parameters on fluid flow and mass transfer during the evaluation of 4-CP degradation in PBR. A CFD model was developed to calculate the optimum level of these parameters to achieve a higher level of 4-CP degradation. Furthermore, the CFD model was authenticated with results obtained from experiments. The process flow diagram followed in this study is illustrated in Fig. S1.

\subsection{Optimization of 4-CP Biodegradation in PBR}

The effect of flow rate on biodegradation of 4-CP was evaluated at $500 \mathrm{mg} / \mathrm{L}$ of inlet concentration of $4-\mathrm{CP}, 18 \mathrm{~cm}$ of bed height, and 0.375 of porosity. In the present experiment, the flow rate was maintained at 1.3, 2, and $4 \mathrm{~mL} / \mathrm{min}$. The residence time was calculated as 16, 11 and $5 \mathrm{~min}$, respectively. Fig. 2(a) illustrates the effect of various flow rate on the biodegradation of 4-CP in PBR. Results show that the degradation of 4-CP increases with the enhancement of flow rate. The biodegradation of 4-CP was found to be $69.32 \%$, 76.45 , and $99.31 \%$ at $1.3 \mathrm{~mL} / \mathrm{min}, 2 \mathrm{~mL} / \mathrm{min}$ and $4 \mathrm{~mL} / \mathrm{min}$, respectively. Enhancement of flow rate decreases the residence time of the substrate in the PBR; therefore, a higher level of 4-CP degradation is expected. However, a comparatively higher percentage of 4-CP degradation is found at lower residence time. The above finding is due to the decrease of mass transfer resistance between the boundary layer and solid surface. In heterogeneous reaction, mass transfer resistance plays a crucial role in the overall efficiency of PBR. The above said resistance could be reduced by increasing the flow rate, which minimizes the thickness of the boundary layer, which is developed on the surface of alginate bead [27]. Therefore, $4 \mathrm{~mL} / \mathrm{min}$ is considered as the optimum flow rate in the present case. To understand the effect of bed height on the degradation of 4-CP in PBR, various experiments were carried out at different bed heights $(14,16$ and $18 \mathrm{~cm})$ and the percentage of degradation was measured. During the experiment, flow rate, inlet concentration of 4-CP and porosity were kept at $4 \mathrm{~mL} / \mathrm{min}, 500 \mathrm{mg} / \mathrm{L}$ and 0.375 , respectively. The residence time of fluid was calculated as 4.1, 4.7, and 5 min at bed height of 14,16 , and $18 \mathrm{~cm}$ respectively. It is evident that the maximum degradation of $4-\mathrm{CP}$ is found to be $99.23 \%$ at 18 cm of bed height, followed by $53.46 \%$ and $73.07 \%$ at bed height of 14 and $16 \mathrm{~cm}$, respectively (Fig. 2(b)). Since higher bed height contributes more residence time of fluid, which augments the catalytic process inside the PBR. Therefore, higher degradation of 4-CP is obtained in the present case [27]. Fig. 2(c) illustrates the effect of inlet concentration of 4-CP on degradation in PBR. These experiments were carried out at various inlet concentration of 4-CP (500 mg/L, $750 \mathrm{mg} / \mathrm{L}$, and 1,000 mg/L) when bed height, flow rate, and porosity were fixed at $18 \mathrm{~cm}, 4 \mathrm{ml} / \mathrm{min}$ and 0.375 , respectively. Fig. 2(c) depicts that as the concentration of 4-CP increases, the percentage of degradation is found to decrease. Since 4-CP is a sole carbon source present in media, therefore, bacteria consume it to maintain their metabolic activity. However, due to the toxicity of 4-CP, bacteria can tolerate a certain concentration of 4-CP. 

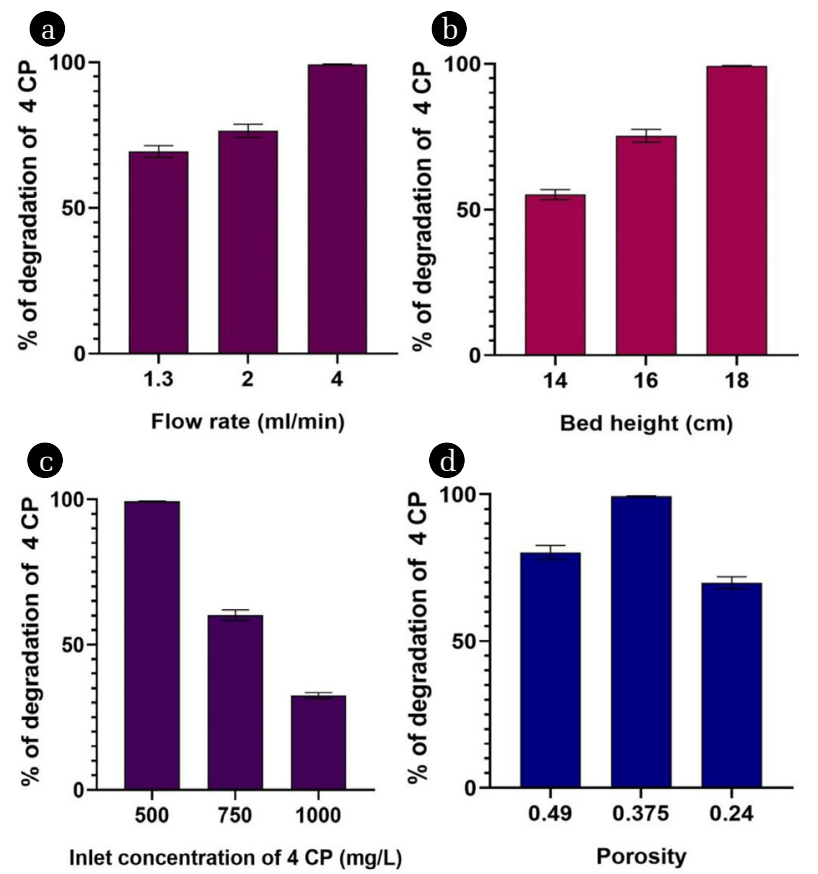

Fig. 2. Effect of (a) Flow rate, (b) Bed height, (c) Inlet concentration of 4-CP, (d) Porosity of bed on 4-CP degradation in packed bed reactor.

Results show that the higher degradation of 4-CP was observed to $99.23 \%$ at $500 \mathrm{mg} / \mathrm{L}$ of inlet concentration of 4 -CP. It is also evident that $58.31 \%$ and $31.47 \%$ of $4-\mathrm{CP}$ degradation are found at $750 \mathrm{mg} / \mathrm{L}$ and $1,000 \mathrm{mg} / \mathrm{L}$ of inlet concentration of 4-CP, respectively. In our previous experiment, it was found that B. subtilis MF447840.1 can able to degrade 4-CP up to a concentration of 1,000 mg/L; however, the specific degradation rate was found to decrease from $500 \mathrm{mg} / \mathrm{L}$ to $1,000 \mathrm{mg} / \mathrm{L}$ [16]. To understand the role of bed porosity on the degradation of 4-CP in PBR, various alginate bead (2, 4 and $6 \mathrm{~cm})$ were used in PBR and percentage of 4-CP degradation was measured. During these experiments, inlet concentration, bed height, and flow rate were fixed at $500 \mathrm{mg} / \mathrm{L}, 18 \mathrm{~cm}$ and $4 \mathrm{~mL} / \mathrm{min}$, respectively. Fig. 2(d) depicts that the degradation of 4-CP is increased with enhanced porosity from 0.24 to 0.375 . However, further enhancement of porosity decreases the 4-CP degradation in PBR. The enhancement of porosity from 0.24 to 0.375 , decreases pressure drop inside the PBR. It also augments the residence time of fluid in PBR. The residence time of PBR was measured as 3.4 and 5 min for 0.24 and 0.375 of porosity, respectively. Therefore, higher contact time ( $5 \mathrm{~min}$ ) between 4-CP and B. subtilis MF447840.1 is found in 0.375 of porosity of packed bed, which elevates the degradation of 4-CP. The enhancement of porosity from 0.375 to 0.49 of bed decreases the conversion of 4-CP in PBR, which may be due to reducing of contact time between substrate and catalyst, although, the residence time of PBR is increased to $7 \mathrm{~min}$ in the presence of 0.49 of porosity of bed [28]. The present finding states that maximum degradation of 4-CP (99.23\%) is found in PBR in $18 \mathrm{~cm}$ of bed height, $4 \mathrm{~mL} / \mathrm{min}$ of flow rate, $500 \mathrm{mg} / \mathrm{L}$ of inlet concentration and 0.375 of porosity which conditions are considered as optimum for 4-CP degradation in PBR.

\subsection{Grid Optimization Test}

A grid optimization test study [29] was conducted using the concentration of 4-chlorophenol $(1000 \mathrm{mg} / \mathrm{L})$ in wastewater at a flow rate of $4 \mathrm{~mL} / \mathrm{min}$. The liquid flows through the immobilized catalyst packed bed reactor column (height $18 \mathrm{~cm}$ ). The size of the immobilized catalyst is spherical having a diameter of 6,4 and $2 \mathrm{~mm}$, and the porosities $(\varepsilon)$ of the bed containing the various size of catalyst are $0.49,0.375$ and 0.24 , respectively. Here, the three-grid sizes were used, and the mass imbalance results from the CFD simulation were compared with the experimental results. From this study, it was observed that the results for the fine grid (nodes: 45943, cells: 236995) matches better with the experimental results than the other grids based on \% error (6.02). The computer memory cost, stability, convergence, and accuracy were given for various grids in Table S1. Fig. 3(a) shows the tetrahedral grid for the immobilized catalyst bed reactor, and its sectional view is illustrated in Fig. 3(b). Results show that the resolution of present mesh is adequate to attain the solutions for grid-independent study in the model proposed in the present case. An enormous number of time steps were shown better accurateness but take longer to achieve convergence ( $\left(10^{-3}\right.$ for continuity and $10^{-5}$ for momentum). In this case, the fine grid is optimal due to accuracy and stability.
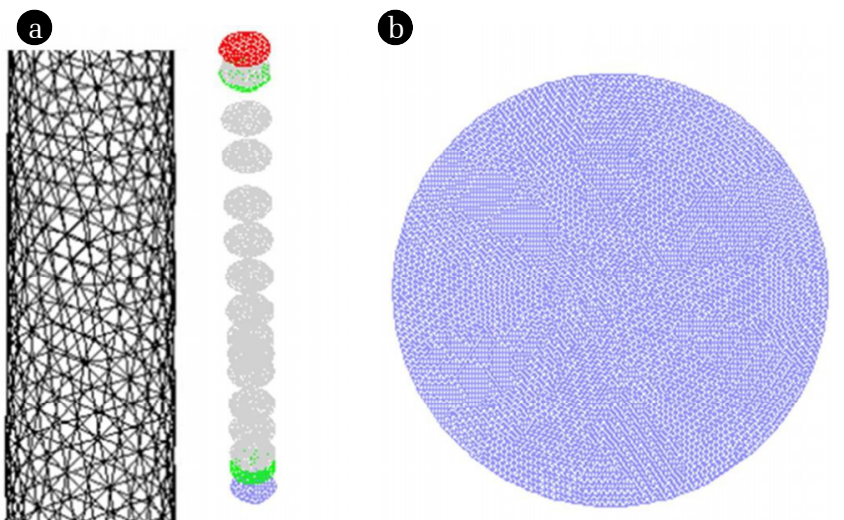

Fig. 3. (a) Tetrahedral grid of packed bed reactor and (b) Sectional view of the reactor.

\subsection{CFD Analysis}

Gambit 6.3 and Fluent 6.3 software was used for simulation study of flow of liquid inside the PBR. Initially, the geometry of the immobilized catalyzed bed reactor was drawn in Gambit 6.3. The tetrahedral mesh was constructed in the computational flow domain of the reactor. The inlet, outlet boundary, and continuum types were specified. The mesh was examined to ensure the label of high skewness should be below 0.9 for the tetrahedral mesh. Mesh file so prepared by Gambit 6.3 was imported to Fluent 6.3, and the mesh was further checked. Several features such as 3-D, steady, implicit, and pressure-based solver were defined. Once the features were defined, single-phase laminar porous-zone model was activated, and the laminar porous-zone model was defined [30]. The said model follows the Kozeny-Carman equation or Darcy's law. The properties of 4-CPunder the laminar flow conditions was enabled using the command in text to define/models/viscous/laminar. The Newtonian properties of wastewater (4-chlorophenol + water), tem- 
perature, viscosity values, and the inlet velocity were included. The selection of operating conditions was carried out through turning on gravity, and the operating density was demarcated. Under relaxation factors of solution control methodology, the pressure and momentum were set as 0.5 and 0.3 , and default values were kept for the other parameters. Under standard schemes, STANDARD was considered for momentum, and first-order upwind was selected for other variables. Pressure-velocity was used as SIMPLE coupling. Once the features were set, initialized the solution to velocity and the plotting of residuals were enabled during the calculation. The convergence criteria for default were maintained to $1 \times 10^{-5}$ for all residuals except that of the transport equation, in which the residual was set to $10^{-3}$. The contour plot of the pressure drop, friction factor, and concentration profile was performed.

\subsection{Mass Transfer Study}

Fig. 4 illustrates the mass imbalance and contour plot of 4-CP inside the immobilized packed bed reactor (PBR). The impact of flow rate was firstly investigated in PBR (Fig. 4(a)) as the inlet flow rate affects the degradation rate and intrinsic kinetics of reactor significantly. The various flow rates, namely, $1.3,2$, and $4 \mathrm{~mL} / \mathrm{min}$, were used to understand mass imbalance inside immobilized PBR. CFD analysis showed that the outlet concentration of 4-CP was gradually decreased as the height of bed increased, which may be due to the increase of residence time of fluid inside PBR [31]. Fig. 4(a) illustrates that the outlet concentration of 4-CP was found to be minimum in the presence of $4 \mathrm{~mL} / \mathrm{min}$ of flow rate when compared with other flow rates under the present experimental condition. The present finding is due to the decline of mass transfer resistance inside the boundary layer of the bulk concentration of 4-CP and solid surface of alginate bed. It is obvious that high flow rate decreases the residence time of fluid inside PBR, however, the optimum flow rate of fluid is required to decrease the thickness of boundary layer which leads to decline the mass transfer resistance

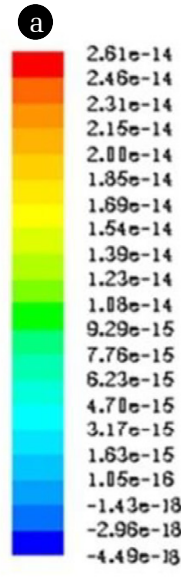

(a)

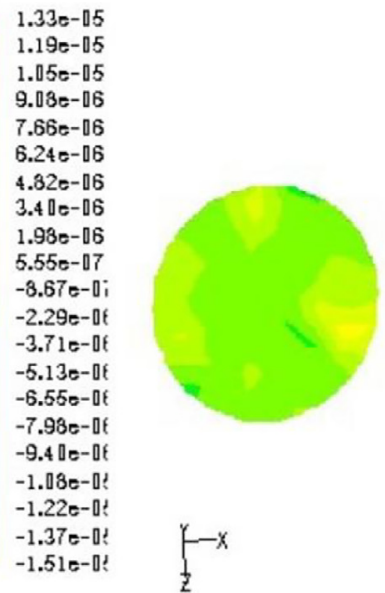

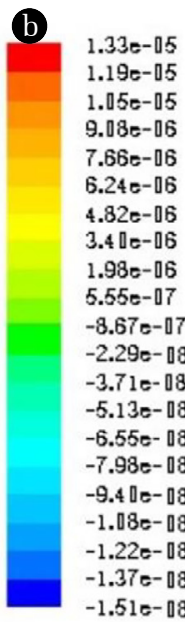
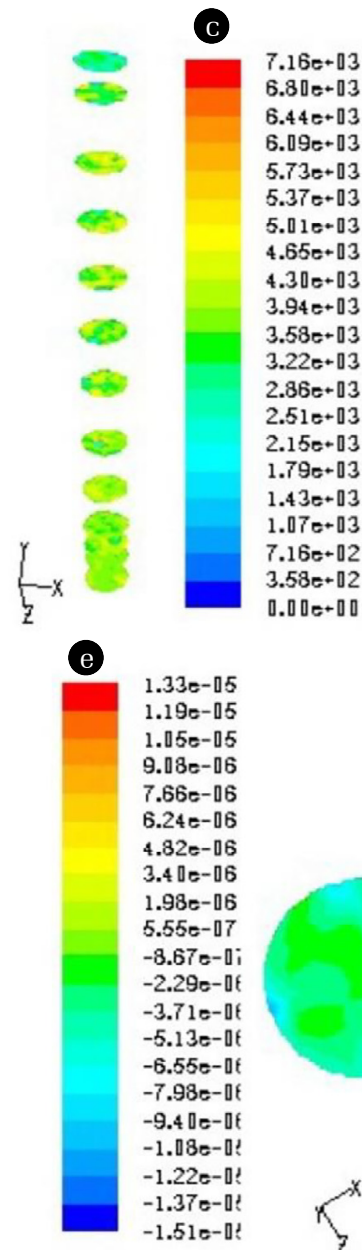
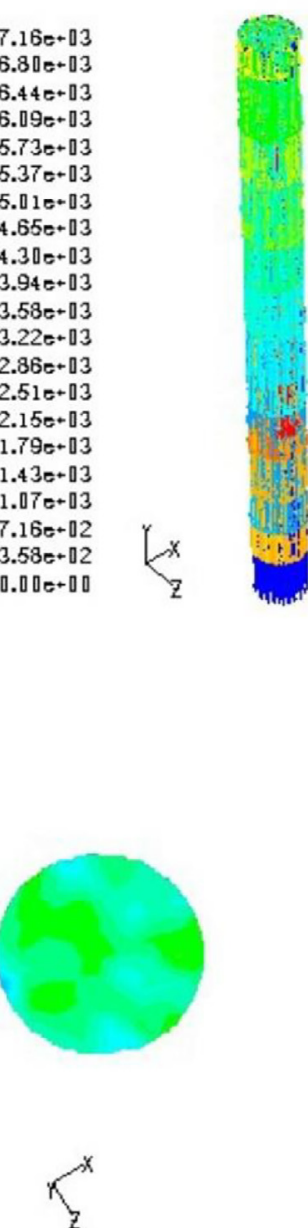

Fig. 4. (a) Profiles of mass imbalance in packed bed reactor at fixed $18 \mathrm{~cm}$ of bed height and $1000 \mathrm{mg} / \mathrm{L}$ of 4 -CP concentration in waste water with $4 \mathrm{ml} / \mathrm{min}$ of flow rate and 0.375 of porosity, (b) Profiles of mass imbalance in packed bed reactor at fixed $18 \mathrm{~cm}$ of bed height and $500 \mathrm{mg} / \mathrm{L}$ of $4-\mathrm{CP}$ concentration in waste water with $4 \mathrm{ml} / \mathrm{min}$ of flow rate and 0.375 of porosity, contours of (c) Path line (particle distribution) and mass imbalance $(\mathrm{kg} / \mathrm{s}$ ) of (d) Inlet (e) Outlet for the $1000 \mathrm{mg} / \mathrm{L}$ concentration of $4-\mathrm{CP}$ in waste water and $4 \mathrm{ml} / \mathrm{min}$ of flow rate in the packed immobilized catalyst bed reactor with $18 \mathrm{~cm}$ of bed height and 0.375 of porosity. 
of 4-CP from bulk fluid to the surface of alginate bed [27]. The effect of inlet concentration of 4-CP was further investigated, and results were given in Fig. 4(b). Since degradation kinetics depends on the concentration of 4-CP available near the vicinity of catalyst, therefore, it might have a significant role in the overall degradation of 4-CP. The outlet concentration profile of 4-CP concerning bed height has been illustrated in Fig. 4(b). The concentration of 4CP in effluent decreases as the height of bed increases. It was found that $500 \mathrm{mg} / \mathrm{L}$ of inlet concentration of $4-\mathrm{CP}$ is suitable for the present study as outlet concentration of 4-CP was found to be minimum in compare with 750 and $1000 \mathrm{mg} / \mathrm{L}$ of inlet 4-CP concentration. It is obvious that the biodegradation rate increases as the inlet concentration of 4-CP increases; however, the detrimental effects of biocatalyst was found at $1,000 \mathrm{mg} / \mathrm{L} \mathrm{[16].} \mathrm{It} \mathrm{is}$ evident that the bed height of PBR has a crucial role in degradation; therefore, the impact of bed height on outlet concentration of 4-CP was studied. Results showed that $18 \mathrm{~cm}$ of bed height is suitable for the present study (Data not shown) as it gave maximum residence to degrade $4-\mathrm{CP}$. Therefore, $500 \mathrm{mg} / \mathrm{L}$ of inlet concentration of 4-CP, $4 \mathrm{~mL} / \mathrm{min}$, and $18 \mathrm{~cm}$ of bed height were found to be optimum for 4-CP degradation study. The effect of porosity on outlet concen- tration of 4-CP was further study at optimum parameters as stated above and experiment were carried out at various porosity of 0.49 , 0.375 , and 0.24 . The outlet 4-CP concentration in effluent of waste water decreases as bed height increases (Data not shown). This is due to the greater availability of catalyzed contact surface area and, hence, contacts time with the 4-chlorophenol-containing wastewater. The porosity of 0.375 was found to be optimum. The path line, particle distribution, and inlet-outlet mass imbalance of 4-chlorophenol in the packed immobilized catalyzed bed reactor are illustrated in Fig. 4(c), 4(d), and 4(e). It is evident from results that the concentration of 4-CP is gradually decreased with increase of bed height inside the PBR. The heterogeneous catalytic reaction is mostly involved for removal of 4-CP from the wastewater.

\subsection{Hydrodynamics Study}

Fig. 5(a) illustrates a contour plot of static pressure inside the immobilized packed bed reactor. It has been found that static pressure decreases as bed height increases inside PBR, which is due to developed pressure during fluid movement from bottom to top of the packed bed reactor. This phenomenon strengthens with increasing flow rate, due to the increase in kinetic energy loss
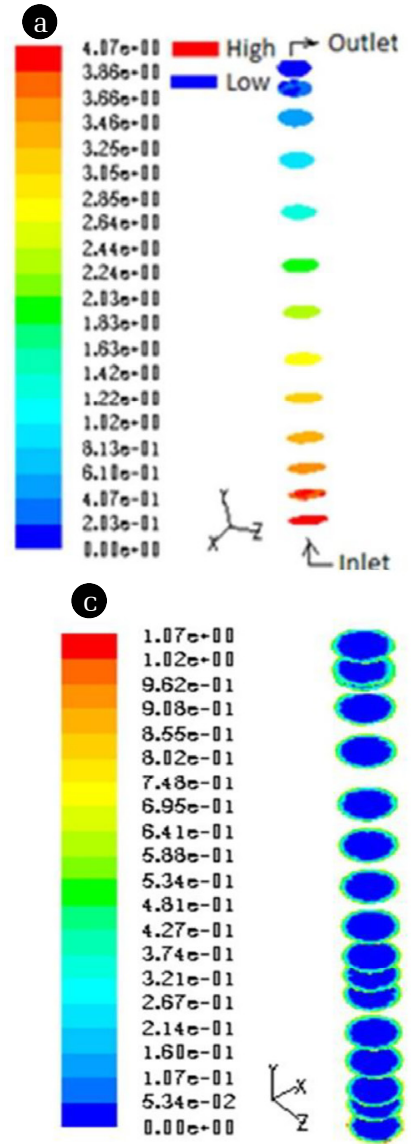
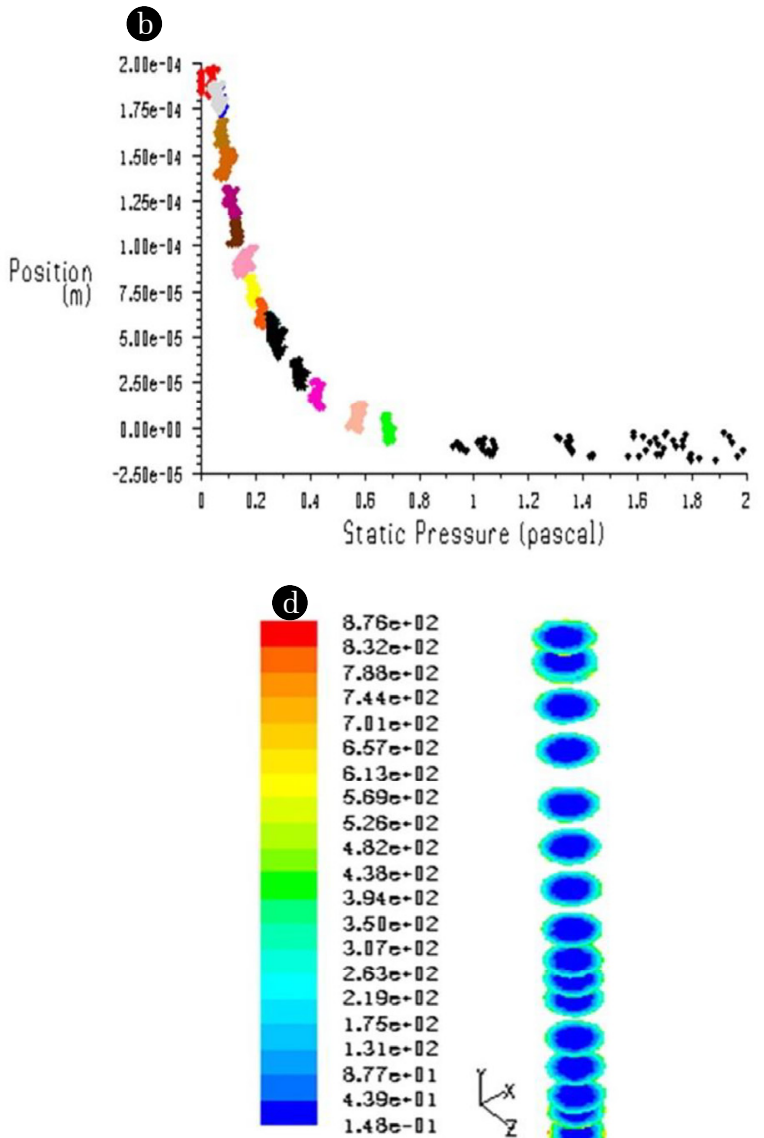

Fig. 5. (a) Contours of static pressure (Pa) in packed bed reactor at $18 \mathrm{~cm}$ of bed height and $1000 \mathrm{mg} / \mathrm{L}$ of fixed 4-CP concentration in waste water with $4 \mathrm{ml} / \mathrm{min}$ of flow rate and 0.375 of porosity, (b) Pressure distribution inside PBR, and profiles of (c) Wall shear stress (Pa) and (d) Shear strain (1/s) in packed bed reactor at $18 \mathrm{~cm}$ of bed height and $1000 \mathrm{mg} / \mathrm{L}$ of inlet 4-CP concentration in waste water and $4 \mathrm{~mL} / \mathrm{min}$ of flow rate and 0.375 of porosity. 

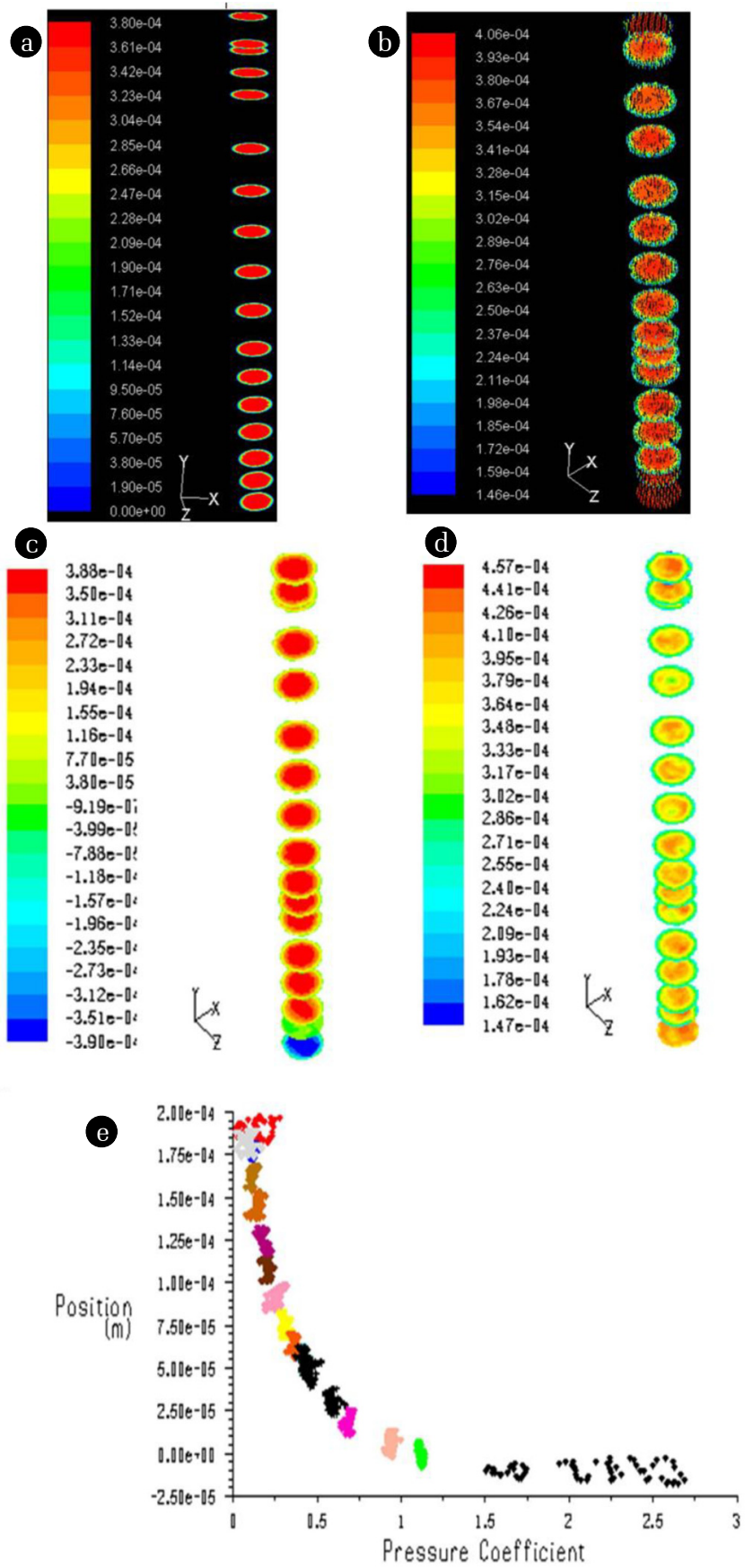

Fig. 6. Contours of (a) Velocity magnitude $(\mathrm{m} / \mathrm{s})$, (b) Velocity vector $(\mathrm{m} / \mathrm{s})$, (c) Radial velocity $(\mathrm{m} / \mathrm{s})$, (d) Cell Reynolds Number in the packed bed reactor (height $180 \mathrm{~mm}$ ) at $1000 \mathrm{mg} / \mathrm{L}$ of 4-CP concentration with flow rate of $4 \mathrm{~mL} / \mathrm{min}$ and 0.375 of porosity, contours of (e) pressure coefficient in the packed bed reactor at $18 \mathrm{~cm}$ of bed height and $4 \mathrm{~mL} / \mathrm{min}$ of flow rate along with $1,000 \mathrm{mg} / \mathrm{L}$ of $4-\mathrm{CP}$ concentration and 0.375 of porosity.

resulting from the flow obstruction and resistance. The distribution of pressure drop inside the immobilized packed bed reactor was illustrated in Fig. 5(b). It is evident that static pressure decreases with the increase of bed height of the PBR. This phenomenon strengthens within creasing bed height (from $14-18 \mathrm{~cm}$ ) of the packed bed reactor. The increase in the bed height increases the flow resistance and contact time due to the increase in the available contact surface area of the packed catalyst bed with wastewater, which increases the kinetic energy loss [32]. The impact of porosity on static pressure was further investigated. It indicates that the static pressure does not change with increasing void fraction. However, it will gradually decrease with bed height from the inlet to outlet of the packed bed. Fig. 5(c) illustrates the contour of the wall shear stress, and the shear strain is high near the wall of the packed catalyst bed and low at the center of the void space (Fig. 5(d)). This is due to the greater velocity gradient near the wall and less at the center. Fig. 6(a), (b), (c), and (d) illustrate the contour plots of the velocity magnitude and vector, radial velocity, and Reynolds number respectively inside PBR. In all cases, the velocity is high at the center and less at the wall. Fig. 6(e) illustrates the contour plot of the pressure coefficient, which gradually increases with bed height. This is due to the loss of kinetic energy from the friction and obstruction of flow by the immobilized catalyst.

\subsection{Validation}

Fig. 7(a) shows experimental and predicted values of percentage of 4-CP degradation on various flow rates in immobilized catalyst PBR with fixed inlet 4-CP concentration (500 mg/L), bed height $(18 \mathrm{~cm})$ and porosity $(0.375)$. It is evident from Fig. 7(a) that experiment and predicted values of 4-CP degradation are increased as the flow rate is augmented from $1.3 \mathrm{~mL} / \mathrm{min}$ to $4 \mathrm{~mL} / \mathrm{min}$. It is obvious that enhancement of flow rate in PBR decreases the residence time; however, an increase of 4-CP degradation at a higher flow rate $(4 \mathrm{~mL} / \mathrm{min})$ may be due to a decrease of resistance of mass transfer from the bulk fluid to the alginate bed surface. Therefore, both experiment value and numerical model (CFD analysis) show the reduction of 4-CP concentration in effluent with the enhancement of flow rate. Paired " $\mathrm{t}$ " test has been carried out between the percentage of 4-CP degradation from experiment and numerical model and "p" value is found to be 0.0074 . Since p-value lower than $0.05(\mathrm{p} \leq 0.05)$ is considered significant, therefore, the numerical model can be used to explain the 4-CP degradation in PBR. Fig. 7(b) illustrates the effects of bed height on the percentage of 4-CP degradation obtained from experiment and numerical model in immobilized PBR at fixed inlet 4-CP concentration (500 mg/L), flow rate $(4 \mathrm{~mL} / \mathrm{min})$ and porosity $(0.375)$. It is evident that $4-\mathrm{CP}$ concentration decreases as the bed height of the immobilized catalyzed bed reactor are increased from $14 \mathrm{~cm}$ to $18 \mathrm{~cm}$. The above finding may be due to the increase of contact area and residence time of fluid in the bed, which influences the mass transfer and reaction. After a comparison of experimental and predicted data, the p-value was calculated and found to be 0.0122 , which is lower than 0.05. Therefore, the CFD model can be used to predict the 4-CP degradation process in PBR. Fig. 7(c) illustrates the results of 4-CP degradation obtained from experiment and numerical model, where experiments were carried out at fixed bed height (18 $\mathrm{cm})$, flow rate $(4 \mathrm{~mL} / \mathrm{min}$ ) and 0.375 of porosity. It has been found that the concentration of 4-CP increases from the outlet of PBR, as the inlet concentration augments from $500 \mathrm{mg} / \mathrm{L}$ to $1000 \mathrm{mg} / \mathrm{L}$. 

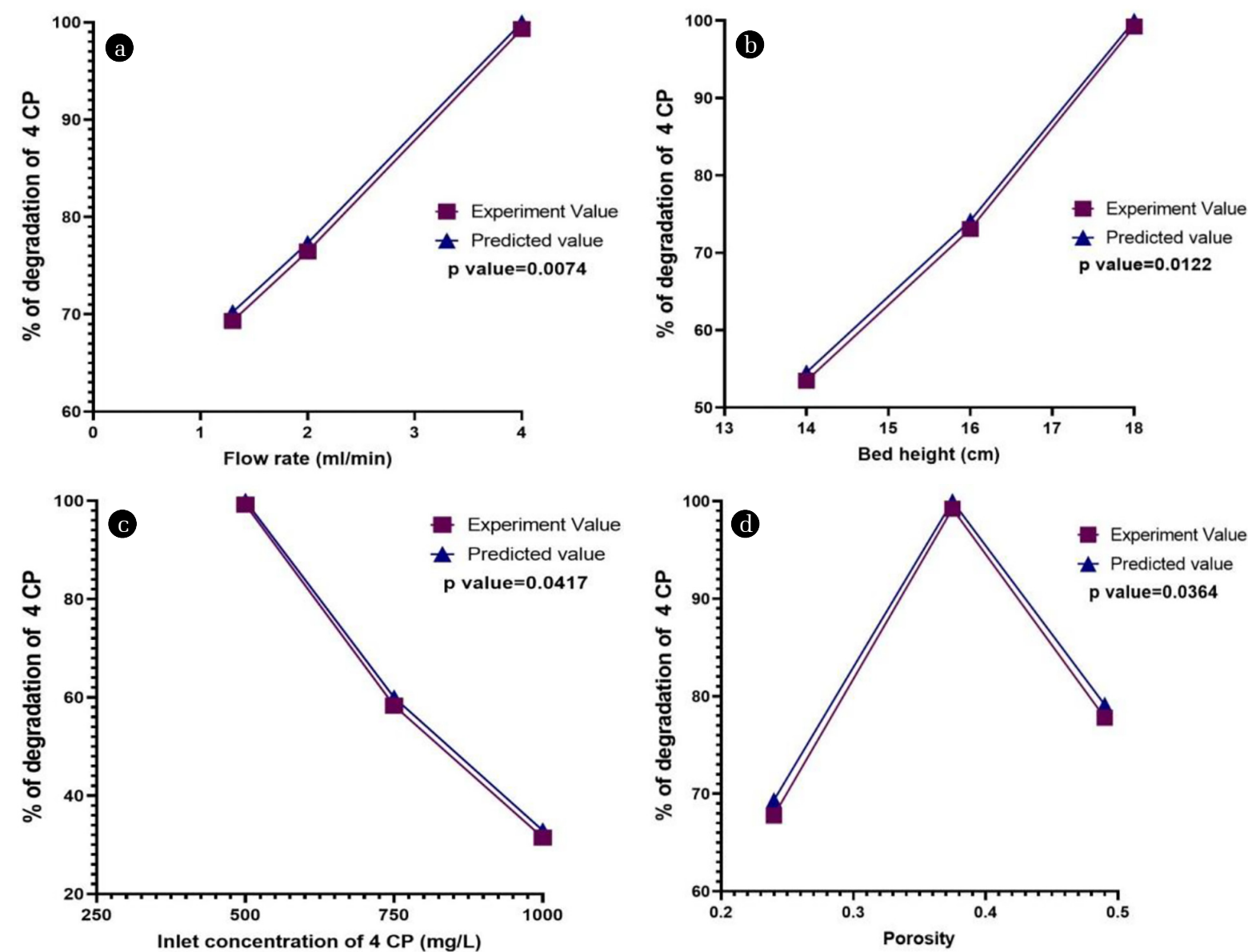

Fig. 7. Experimental and predicted value of (a) Percentage of 4-CP degradation on various flow rates in immobilized PBR at fixed inlet 4-CP concentration $(500 \mathrm{mg} / \mathrm{L})$, bed height $(18 \mathrm{~cm})$ and porosity $(0.375)$ (b) Percentage of 4-CP degradation on various bed heights in immobilized PBR at fixed inlet 4-CP concentration $(500 \mathrm{mg} / \mathrm{L})$, flow rate $(4 \mathrm{~mL} / \mathrm{min})$ and porosity $(0.375)$, (c) Percentage of 4-CP degradation on various inlet concentration of $4-C P i n$ immobilized PBR at fixed bed height $(18 \mathrm{~cm})$, flow rate $(4 \mathrm{~mL} / \mathrm{min})$ and porosity $(0.375)$, and $(\mathrm{d})$ Percentage of 4-CP degradation on various porosities in immobilized PBR at fixed inlet 4-CP concentration (500 mg/L), bed height (18 $\mathrm{cm})$ and flow rate $(4 \mathrm{~mL} / \mathrm{min})$.

Since 4-CP is toxic, therefore, a higher concentration may create a detrimental effect on the biological catalyst. After evaluating the data obtained from experiments and numerical model, it has been found that the data has a minimum variation as the p-value (0.0417) is within 0.05. This study also supports the usability of a numerical model to explain the 4-CP degradation process in PBR. Fig. 7(d) depicts the effects of porosity on 4-CP degradation in PBR, where comparison of data obtained from experiments and CFD model were carried out. The experiments were performed at an inlet concentration of 4-CP of $500 \mathrm{mg} / \mathrm{L}$ with a fixed bed height of $18 \mathrm{~cm}$ and a flow rate of $4 \mathrm{~mL} / \mathrm{min}$. Results depict that the reduced concentration of 4-CP from the outlet of PBR is found with an increase of porosity from 0.24 to 0.375 , which is due to higher residence time and reduction of pressure drop inside the PBR. However, further enhancement of porosity from 0.375 to 0.49 , the outlet concentration of 4-CP from PBR is increased. The above fact may be due to the reduction of contact time between catalyst particle and 4-CP in side PBR. The data obtained from
CFD analysis and experiments were further compared, and the value of $\mathrm{p}$ was calculated as $\mathbf{0 . 0 3 6 4}$, which is lower than 0.05 . Therefore, the CFD model can be used to explain the events of mass transfer and hydrodynamic studies inside the PBR.

\section{Conclusions}

1) Experiments were carried out to evaluate the optimum condition of bed height, flow rate, inlet concentration of 4-CP, and porosity of bed for maximum degradation of 4-CP in immobilized catalyzed packed bed reactors.

2) A CFD model was developed to visualize the mass transfer and hydrodynamics of the 4-CP containing wastewater inside the bed using the ANSYS Fluent software and also to predict the optimal condition required for 4-CP degradation in PBR.

3) Results obtained from both experiments and CFD model show that the percentage of 4-CP degradation depends on the bed 
height, flow rate, inlet concentration of 4-CP, and porosity of bed. Furthermore, the values of static pressure along with pressure coefficients are higher at the inlet of PBR in compare with the outlet of the bed.

4) The wall shear stress, strain rate, velocity, and velocity vectors of fluid inside PBR are easily visualized through CFD analysis. CFD analysis shows that the shear stress and strain rates are higher near the wall of PBR than the center of the reactor, which is due to the variation of the velocity of the fluid in center and wall side of PBR. It is also observed that the values of velocity magnitude and velocity vectors are lower in the wall side of the reactor compared to the center of the bed.

5) The greater mass transfer and faster reaction are found in PBR at the optimized $4 \mathrm{ml} / \mathrm{min}$ of flow rate, $18 \mathrm{~cm}$ of bed height, $500 \mathrm{mg} / \mathrm{L}$ of inlet concentration of $4-\mathrm{CP}$, and 0.375 of porosity of catalyst bed. This is because of the greater contact time and available contact area for mass transfer and reaction inside PBR.

6) The experimental and CFD results are well matched with experimental data as a p-value of data obtained from experiments, and the CFD model is within 0.05 .

\section{Acknowledgment}

This material is based upon work supported by the National Institute of Technology, Agartala, India. Dr. Biswanath Bhunia and Dr. T K Bandyopadhyay express gratitude to Director, National Institute of Technology Agartala for encouragement and support. The authors would like to acknowledge the National Institute of Technology, Agartala, Ministry of Human Resource and Development (MHRD), Government of India for Fellowship (0000-0003-4637-991X).

\section{Author Contributions}

Sudhansu S. (Ph.D. student) conducted all the experiments. S.S. and T.K.B. (Assistant Professor) analyse the data, and B.B. (Assistant Professor) wrote the manuscript.

\section{References}

1. Patel BP, Kumar A. Biodegradation of 4-chlorophenol in an airlift inner loop bioreactor with mixed consortium: effect of HRT, loading rate and biogenic substrate. 3 Biotech 2016;6:1-9.

2. Wang Q, Li Y, Li J, et al. Experimental and kinetic study on the cometabolic biodegradation of phenol and 4-chlorophenol by psychrotrophic Pseudomonas putida LY1. Environ. Sci. Pollut. Res. 2015;22:565-573.

3. Cooper V, Nicell J. Removal of phenols from a foundry wastewater using horseradish peroxidase. Water. Res. 1996;30:954-964.

4. Igbinosa EO, Odjadjare EE, Chigor VN, et al. Toxicological profile of chlorophenols and their derivatives in the environment: the public health perspective. Sci. World. J. 2013;2013:1-11.

5. Hu P, Huang J, Ouyang Y, et al. Water management affects arsenic and cadmium accumulation in different rice cultivars. Environ. Geochem. Health. 2013;35:767-778.
6. Arao T, Kawasaki A, Baba K, et al. Effects of water management on cadmium and arsenic accumulation and dimethylarsinic acid concentrations in Japanese rice. Environ. Sci. Technol. 2009;43:9361-9367.

7. Durruty I, Okada E, González JF, Murialdo SE. Multisubstrate monod kinetic model for simultaneous degradation of chlorophenol mixtures. Biotechnol. Bioproc. Eng. 2011;16:908-915.

8. Ra JS, Oh S-Y, Lee BC, Kim SD. The effect of suspended particles coated by humic acid on the toxicity of pharmaceuticals, estrogens, and phenolic compounds. Environ. Int. 2008;34:184-192.

9. Basak B, Bhunia B, Dutta S, Chakraborty S, Dey A. Kinetics of phenol biodegradation at high concentration by a metabolically versatile isolated yeast Candida tropicalis PHB5. Environ. Sci. Pollut. Res. 2014;21:1444-1454.

10. Allonneau C, Olmos E, Guyot S, et al. Hydrodynamic characterization of a new small-scale reactor mixed by a magnetic bar. Biochem. Eng. J. 2015;96:29-37.

11. Habibi A, Vahabzadeh F. Degradation of formaldehyde in packed-bed bioreactor by kissiris-immobilized Ralstonia eutropha. Biotechnol. Bioproc. Eng. 2013;18:455-464.

12. Zilouei H, Guieysse B, Mattiasson B. Biological degradation of chlorophenols in packed-bed bioreactors using mixed bacterial consortia. Process. Biochem. 2006;41:1083-1089.

13. Rezvani F, Azargoshasb H, Jamialahmadi O, et al. Experimental study and CFD simulation of phenol removal by immobilization of soybean seed coat in a packed-bed bioreactor. Biochem. Eng. J. 2015;101:32-43.

14. Amani A, Jalilnejad E. CFD modeling of formaldehyde biodegradation in an immobilized cell bioreactor with disc-shaped Kissiris support. Biochem. Eng. J. 2017;122:47-59.

15. Habibi A, Nalband M, Jalilnejad E. Experimentation and CFD modeling of continuous degradation of formaldehyde by immobilized Ralstonia eutropha in a semi-pilot-scale plug flow bioreactor. Bioproc. Biosyst. Eng. 2019;42:485-497.

16. Sandhibigraha S, Chakraborty S, Bandyopadhyay T, Bhunia B. Kinetic study of 4-chlorophenol biodegradation by the novel isolated Bacillus subtilis in batch shake flask. Environ. Eng. Res. 2020;25:62-70.

17. Hossain SG, McLaughlan RG. Oxidation of chlorophenols in aqueous solution by excess potassium permanganate. Water Air Soil Pollut. 2012;223:1429-1435.

18. Lettmann C, Hildenbrand K, Kisch H, Macyk W, Maier WF. Visible light photodegradation of 4-chlorophenol with a coke-containing titanium dioxide photocatalyst. Appl. Catal B-Environ. 2001;32:215-227.

19. Geankoplis CJ. Transport processes and separation process principles: (includes unit operations).4th ed. Prentice Hall; 2003. p. 1-1056.

20. Bird RB, Stewart WE, Lightfoot EN. Transport phenomena.2nd ed. Wiley; 2006. p. 1-912.

21. Autee A, Giri S. Experimental study on two-phase flow pressure drop in small diameter bends. Perspect. Sci. 2016;8:621-625.

22. McCabe WL, Smith JC, Harriott P. Unit operations of chemical engineering.7th ed. McGraw-Hill; 2017. p. 1-1152.

23. Liu AJ, Ramaswamy S, Mason T, Gang H, Weitz D. Anomalous viscous loss in emulsions. Phys. Rev. Lett. 1996;76:3017.

24. Weinberg M, Candler R, Chandorkar S, et al. Energy loss in 
MEMS resonators and the impact on inertial and RF devices. In: Transducers International Solid-State Sensors, Actuators and Microsystems Conference; 21-25 June 2009; Denver. p. 688-695.

25. Mauchly JW. Significance test for sphericity of a normal n-variate distribution. Ann. Math. Stat. 1940;11:204-209.

26. Astarita G, Marrucci G. Principles of non-Newtonian fluid mechanics.1st ed. McGraw-Hill; 1974. p. 1-289.

27. Doran PM. Bioprocess engineering principles. 2nd ed. Elsevier; 2012. p. 1-926.

28. Levenspiel O. Chemical reaction engineering. 3rd ed. Wiley; 2006. p. 1-688.
29. Díaz AR, Kikuchi N, Taylor JE. A method of grid optimization for finite element methods. Comput. Methods. Appl. Mech. Eng. 1983;41:29-45.

30. Beven K, Young P. An aggregated mixing zone model of solute transport through porous media. J. Contam. Hydrol. 1988;3: 129-143.

31. Wang X, Wen J, Jia X. CFD modelling of transient performance of toluene emissions biodegradation in bubble column. Biochem. Eng. J. 2009;48:42-50.

32. Wang X, Ding J, Guo WQ, Ren NQ. A hydrodynamics-reaction kinetics coupled model for evaluating bioreactors derived from CFD simulation. Bioresour. Technol. 2010;101:9749-9757. 